\title{
History of Canadian Anaesthesia
}

\section{Fifty years in anaesthesia}

\section{Medical school and internship}

I entered medicine at McGill University in September 1919 , with no thought of ever becoming an anaesthetist. This was a six-year course, including the first year of premedicine that comprised biology, organic chemistry, physics and the history of medicine. In the second we added anatomy and physiology. Anatomy had its macabre aspect: the subject of the paper I was required to give in order to be admitted to Alpha Omega Alpha was body snatching, which the Medical Building janitor participated in to equip the anatomy laboratories. As far as anaesthesia was concerned, no formal course was ever given.

It was as a medical student, however, that I was introduced to anaesthesia. For an appendectomy I received chloroform and ether by open mask, given by Dr. John Hepburn, the chief anaesthetist at the Montreal General Hospital. Dr. Hepburn also supervised me when, a little later, I gave my first anaesthetic, to a patient undergoing a hysterectomy. Everything proceeded in a safe manner, but I could see that the surgeon was both irritated and uncomfortable.

I did my internship not in Montréal but at the Toronto General Hospital. There I gave some anaesthetics as an intern - usually the ACE mixture (alcohol 1 part, chloroform 2 and ether 3 ) - and I became familiar with the work of such anaesthetists as Dr. Stanley Campbell, Dr. John Chassels and Dr. Easson Brown. In this period Dr. Campbell, later Professor of Anaesthesia at the University of Toronto, like most of the anaesthetists, also had a general practice, and Dr. Brown served as a coroner as well. I saw some of the great figures in Canadian medicine and surgery: Dr. Duncan Graham, the Professor of Medicine, and Dr. Ray Farquharson, his resident; Dr. K.G. MacKenzie, who had been trained by Harvey Cushing and was Toronto's first neurosurgeon; and Drs. Roscoe Graham and FN.G. Starr, who assisted each other sitting on high stools across the operating table from each other. They all did the best they could in the absence of ef-

*Deceased. Formerly of St. Catharines, Ontario.
Nicholas P. Hill MD*

ficacious drugs. Banting and Best did not produce insulin until after I had left Toronto, we had no liver extract for patients with pernicious anaemia, and the sulphonamides and penicillin were still a long way off.

\section{General Practice}

After leaving Toronto I moved to St. Catharines, Ontario, on August 1, 1927. I sent out cards to the profession stating that I would specialize in obstetrics and gynaecology; I had been senior houseman in Ob-Gyn during my second year of internship. I was hardly overworked, for in five months I saw 40 patients and my cash collections totalled $\$ 300$. My first case, however, was interesting because it reflects the pattern of practice at the time. A patient was referred to me from a doctor who had two patients in labour at the same time. In those days the common thing was to perform deliveries at home, and the referring doctor took the preferred case - the one to be delivered at home. Thus I had the opportunity to deliver, in St. Catharines General Hospital, a single girl with venereal disease. For this I was paid \$15. After starving for six months I went into general practice.

At this time I was already giving an occasional anaesthetic. Some of the anaesthetics, like the deliveries, were given in a patient's home; they were for minor procedures like setting a fractured wrist or a D \& C. For these the fee was $\$ 5.00$. For a procedure in hospital, like an appendectomy, it was \$10; this was for "major" anaesthetic.

When I had been in practice for about 18 months, Dr. Graham Harkness, one of the four senior physicians in the city, chose to take an interest in my career. In the beginning, I served in the operating room as a surgical assistant to Dr. Harkness. The anaesthetic might be given by the referring general practitioner but, more likely, I would. Specialization was rare in those days, and the anaesthetic was considered of less importance than the assistant's job, and soon I was placed around the head end of the table. I decided that, if this were to be my position in the operating room, I should take pains to know more about the art of anaesthesia. So, like many 
other general practitioners across the country, I found that in reality I was becoming an anaesthetist.

Two additional factors helped direct me into the practice of anaesthesia. First, early in 1937, a new Heidbrink gas machine was purchased as an addition to the old McKesson, and I felt that I should become familiar with it. Second, I was doing my own obstetrics and gynaecology but I did recognize that I could not "ride two horses" at the same time.

\section{Early years in anaesthesia}

At this time - at the beginning of the 1930s - the anaesthetic agents were ether and chloroform, and ethyl chloride was useful as an induction agent. The last, however, was given a bad name by Dr. Samuel Johnston, the professor at Toronto, who had it removed from operating rooms of the Toronto General. But in St. Catharines we liked to use it, for it facilitated induction of anaesthesia and helped us avoid laryngospasm. So we continued to use it.

In the 1930s we were still stamping out diseases like diphtheria, and rheumatic fever was a real, threatening entity. We had many patients with damaged hearts. During anaesthesia their need for oxygen was paramount, and so we welcomed the advent of cyclopropane, which could be given with $100 \%$ oxygen.

Well into the 1950s - before the advent of halothane - cyclopropane was a better anaesthetic than we had ever had before. Its potency, its rapidity of action and the fact that it could be used with $100 \%$ oxygen were its great advantages. The principal disadvantages were its flammability and the occurrence of arrhythmias. (To treat the latter we used procaine and procaine amide intravenously.) I learned how to give "cyclo" safely in the operating rooms of the Toronto General Hospital, sitting at the knee of Dr. Harry Shields. He was an excellent teacher; he also gave me good instruction on the use of the Heidbrink. Toronto was, of course, the right place to go to learn about cyclopropane, for it had been developed there and experimented with by George Lucas and Velyien Henderson. Its flammability and perhaps Dr. Johnston's conservative nature led to its being proscribed in Toronto, and it was introduced clinically not in Toronto but in Madison, Wisconsin, by Ralph Waters.

\section{Full-time anaesthesia}

I returned to St. Catharines, started to rely increasingly on cyclopropane, and used the Heidbrink machine with greater assurance. I now considered myself a real anaesthetist. Since this was the era in which a single physician could "wear several hats," it was quite possible for me to obtain a foothold in the specialty. One such versatile physician was Dr. George Zumstein, who prac- tised radiology, pathology, venereology as well as anaesthesia. I remember him well because he anaesthetized me when I had my tonsils removed. I did not wish to have chloroform and ether - certainly not for induction - so Dr. Zumstein anaesthetized me using nitrous oxide by means of the nose-piece of the McKesson machine. However, after one tonsil had been removed I came out of the anaesthetic; I could feel the clamp in my throat - an early case of awareness. Dr. Zumstein promptly administered chloroform by open mask, and the operation was successfully completed.

Versatility in medical practice in those days was encouraged by the structure of the active staff at St. Catharines Hospital. When I arrived in 1927 a group of some six doctors made up the staff. In about 1931 four groups of physicians, with three in each group, were set up, and I was invited to join the staff. Each group was led by a chief; I was in Dr. Harkness's group. In any one month two groups would be active, and a rotation was worked out so that three of us would cover surgery in the wards for "free" patients, and three would do the same for medicine. In the case of surgery, if an operation was performed by the chief, one member would assist and the other would give the anaesthetic. To a considerable extent we learned "on the job." Until the late 1930s, for example, I had done little or no endotracheal anaesthesia, and it was Dr. Clare Anderson, who had been formally trained under Dr. Charles Stewart at the Montreal General Hospital, who taught me this technique. And so, when the staff was further reorganized in 1948 into departments rather than groups, I had indeed "become" an anaesthetist, and I was ready to accept the post of chief of anaesthesia.

\section{Further advances in anaesthesia}

By this time I had been in practice for almost a quarter of a century, and anaesthesia was still fraught with difficulties. Our machines were the Heidbrink, which worked well, and the McKesson, which, providing only nitrous oxide and oxygen, was not easy to use with proficiency. Thiopentone had only recently been introduced, and we were similarly finding our way with dtubocurarine. Intubation had to be performed very quickly: since we were using cyclopropane, we did not have much time, once we had lifted the face-mask, before anaesthesia would lighten - though we could, and did, facilitate the procedure by adding ether vapour. (Succinylcholine had not yet been introduced.) A further problem was that we were starting to do more involved surgery. Our first gastrectomy, for example, was performed in 1944. I gave the anaesthetic, combining a spinal anaesthetic with dibucaine with cyclopropane as the inhalational agent. 
Spinal anaesthesia, though eschewed in some places, was an important part of our practice. I had given my first spinal in 1934, using procaine for a Caesarean section. By $1940 \mathrm{I}$ became interested in the mechanics and effects of spinal anaesthesia and in other agents besides procaine. I used dibucaine for the first time in 1938 and tetracaine in 1944. In Canada one who stimulated my interest in spinal anaesthesia was Dr. Russell Fraser, of Hamilton. Patterning my practice on what he did, I started to use heavy tetracaine, diluted. The weighting solution was $10 \%$ glucose and the diluent was distilled water. Encouraged by Dr. Fraser, who used 0.1 and $0.2 \%$ solutions of tetracaine, I developed a technique using $0.12,0.13,0.14$, and $0.15 \%$ solutions, though I came to favour $0.14 \%$. I enjoyed this technique, which relied in part on positioning the patient to control the level of anaesthesia. I found that both dibucaine and tetracaine paralyzed the sensory nerves to a higher level than were the motor nerves. When I got into difficulties I would call for advice or help on Dr. Fraser or Dr. Kenneth Heard, of Toronto.

Dr. Heard was helpful again when I began using pentothal in 1943. I furthered my education by visiting him at St. Michael's Hospital. Following this visit, I greatly increased my use of the drug, which seemed the greatest boon of all time for the patient, who no longer had to be aware of the mask over the face. At the same time, we frowned on the directive of surgeons to "give the patient just a little thiopentone"; we believed that there was no such thing as a minor anaesthetic. Thiopentone augmented our armamentarium nicely, for we came to use a combined technique: we would give a spinal, and then put the patient asleep with either thiopentone or cyclopropane, or both, and sometimes nitrous oxide. I soon learned that if I replaced cyclopropane with nitrous oxide towards the end of the anaesthetic my patients recovered more quickly.

Another great advance, of course, was the introduction of d-tubocurarine by Harold Griffith, of Montréal, in 1942. The original product was Squibb's Intocostrin. In reviewing my anaesthetic record cards, I find that I often did not intubate when using d-tubocurarine. I had found out very early that I could "bag" the patient with the mask only, without inflating the stomach, if done gently. We did find that d-tubocurarine helped us somewhat with tracheal intubation, which was becoming more standard a technique.

Two other relaxants I used were decamethonium and succinylcholine. I liked the former, which maintained its action for $45 \mathrm{~min}$ as opposed to the shorter period of the form of d-tubocurarine that we were using. I seldom used succinylcholine and other relaxants such as gallamine and syncurine.

\section{The continuing expansion of the horizon of anaesthesia}

With the years, therefore, I saw the horizon of anaesthesia steadily expand, as more and more drugs (from the original inhalational agents to potent intravenous agents, including Innovar) and techniques were introduced.

Two noteworthy drugs were trichlorethylene and halothane. While I did not use the latter to any great extent - I continued to use cyclopropane until 1967 and I did not start using halothane until 1963 - I came to use trichlorethylene extensively. It was useful in obstetric anaesthesia, and in anaesthetizing patients in the Emergency Department, for they would wake up quickly. But to begin with, as I felt I should see trichlorethylene rather than just read about it, I visited Dr. Alan Noble in Kingston, at the Hotel Dieu. Working with Dr. Noble was Dr. Harold Carman, who developed a tubing hook-up on the Heidbrink machine to bypass the carbon dioxide absorber and obtained good results. (Later, I used trichlorethylene via the Cyprane vaporizer and then the McGill and Duke vaporizers.) I also learned how to use trichlorethylene from Drs. Digby Leigh and Harold Slater at the Montreal Children's Hospital.

As far as techniques were concerned, three in particular expanded my horizon: continuous spinal anaesthesia, epidural anaesthesia for infants, and the application of ventilators.

My interest in continuous spinal anaesthesia was aroused by a presentation given by Dr. Hardman, of London, Ontario, in 1950, though I knew that Dr. Fraser had been interested in the technique in the 1940s. I used a No. 16 Tuohy needle and a No. $31 / 2$ radio-opaque ureteral catheter; during the 1950 s I probably used the technique on some 60 or 70 occasions. I preferred this technique to that consisting of the Lemmon malleable needle and a split mattress. I was more comfortable with the catheter technique, though I once made the cardinal error of trying to withdraw the catheter through the needle and shearing it and leaving a piece in the spinal canal. Fortunately, no harm ensued.

Concern about different aspects of spinal anaesthesia was not misplaced, for many lawsuits gained publicity in both the United States and the United Kingdom. To determine what the right course should be when performing spinal anaesthesia in its different forms, I discussed the topic with many individuals, particularly Dr. Harry Botterell, the neurosurgeon, and Dr. Ron Stephen, formally of Montréal and then of Duke University. I was impressed by a list of safety factors made up by Dr. Stephen, and I drew up my own list of precautionary measures. Although the use of spinal anaesthesia decreased during my career, in part due to the advent of the muscle relaxants and in part to medicolegal concerns, I con- 
tinued to administer spinal anaesthetics in fair number until 1960 and occasionally thereafter.

An allied technique that gave me good results was epidural anaesthesia in infants, particularly those with pyloric stenosis. I heard Dr. Frank Ruston, of Hamilton, talk on this in 1954. My interest thus piqued, I successfully put the technique into practice in anaesthetizing a moribund infant three weeks of age. The result was excellent, with good relaxation. I used this technique in the late 1950s, and when possible I would do so as an alternative to inhalational anaesthesia.

As an anaesthetist I was naturally interested in respiratory physiology and, with the increasing use of ventilators in the 1960s, I determined to learn as much as I could about yet another of the many advances in anaesthesia that I had experienced in my own career. I spent almost a week in March 1968 in the operating rooms of the Royal Victoria Hospital in Montreal with Dr. Noble, and I took a course at the Cleveland Clinic in the same year. Another Canadian, Dr. H. Barrie Fairley, was a prominent advocate of the use of ventilators, and I seemingly pursued him around the country as he delivered papers on the subject. When I felt I had acquired some proficiency in the theory and practice of mechanical ventilation, I commenced to apply controlled ventilation in my own practice. I finally gave up manual ventilation, which a number of centres were for long reluctant to do.

\section{Envoi}

So, as I approached my intended retirement on December 1, 1972, when I was 70, I looked back on my career to see how it was that I had become an anaesthetist. I felt I had become an anaesthetist at first by default; but, out of increasing interest in advances that I had regularly endeavoured to master and apply in my own practice, I came to agree that I had even been, albeit in a small way, a pioneer. During the period in which I practised, anaesthesia in Canada was a progressive specialty, in large part because "there were giants in the land in those days" - men like Wesley Bourne, Harold Shields, Harold Griffith, Digby Leigh, Georges Cousineau and Fernando Hudon - who were always ready to teach and from whom I was always ready to learn. The half-century from 1922 to 1972 was a remarkable period in anaesthesia, for many advances shaped and reshaped its practice. If I was a pioneer it was only because I wished at all times to familiarize myself with these advances and to extend the benefits of them to my patients. 